\title{
USING SIMULATION OPTIMIZATION AS A DECISION SUPPORT TOOL FOR SUPPLY CHAIN COORDINATION WITH CONTRACTS
}

\author{
Hamidreza Eskandari \\ Mohamad Darayi \\ Tarbiat Modares University \\ Advanced Simulation Lab \\ School of Industrial Engineering \\ Tehran, 14117, IRAN
}

\author{
Christopher D. Geiger \\ University of Central Florida \\ Dept. of Industrial Engineering and Management \\ Systems \\ Orlando, FL 32816, USA
}

\begin{abstract}
ABSRACT
This paper studies the issue of channel coordination for a supply chain consisting of one supplier and two retailers, facing stochastic demand that is sensitive to both sales effort and retail price. We develop a decision support tool using simulation optimization for supply chain coordination with revenue sharing or buyback contract. In order to represent a real competitive price and effort dependent demand, a new linear demand model is proposed. Due to the stochastic nature of the market demand and the interaction between decision variables, simulation could help us modeling and analyzing the problem. Simulation optimization is then used to find the optimum or near optimum set of decision variables in the cases of centralized supply chain and coordinated supply chain with contracts.
\end{abstract}

\section{INTRODUCTION}

Supply chain coordination (SCC) can be followed by exerting centralized or decentralized decisionmaking approaches. In a centralized supply chain, there is a unique decision maker who should possess all information on the whole supply chain that is effective in decision making process. In a decentralized supply chain, several independent actors make decision considering their own profit function. In such a decentralized supply chain lack of coordination leads to double marginalization and bullwhip effect (He et al. 2009). The centralized control assures SCC but it may not be realistic (Giannoccaro and Pontrandolfo 2004). Hence, coordination mechanisms are necessary to encourage independent decision makers to pursue channel coordination. Supply chain (SC) contracts as a coordination mechanism could help the supply chain independent members manage their dependencies in order to achieve channel coordination. Supply chain contracts are set of stipulations that suggest suitable information and incentive mechanism to guarantee all SC members to attain coordination and optimize the SC performance.

Supply chain coordination with contracts is thoroughly studied by Cachon (2003). The basis of contracts has originated from the classical newsboy problem. Hence, it is used to model SCC with contracts in different ways. Wang et al. (2004) studied SCC with contracts consists of one supplier and one retailer with stochastic demand. Giannoccaro and Pontrandolfo (2004) extended the problem by considering three-stage SC consists of one manufacturer, one distributer and one retailer. Yao et al. (2008) analyzed the SCC with Revenue Sharing (RS) contract where SC consists of one supplier and two competing retailers. He et al. (2009) considered a condition in which the stochastic market demand is sensitive to both retail price and sales efforts. Although, the trend of the literature indicates that researchers tend to make the problem as close as possible to the real market condition, the complexity of the real situation makes it hard to just analytically face the problem. 
We consider a supply chain with a supplier and two competing retailers. The retailers face a random demand that is sensitive to both retail prices and sales efforts. The two retailers are equally powerful to compete in a common market. Knowing the characteristics of demand, the supply chain members try to tune the contracts parameters to achieve channel coordination. Assuming a single period stochastic demand with known cost parameters and competing factors, two types of contracts have been discussed. In a decentralized supply chain, retailers define their order quantities considering their profit function. It is shown that in the case of centralized supply chain considering the whole SC profit function, the amount of order quantities increased and it is beneficial just for the supplier not for the retailers (Cachon 2003). It is the problem that how we could set the contracts parameters to induce the retailers associating in the SCC mechanisms. Buy back and RS contracts have been used to achieve supply chain coordination. In the buyback contract, supplier purchases unsold products in retailers to share their risks, however, in RS contract, supplier reduces the wholesale price and in turn retailers share their revenue with the supplier (Arshinder et al. 2009).

This paper studies the issue of channel coordination for a SC consisting of one supplier and two retailers, facing stochastic demand that is sensitive to both sales effort and retail price. It differs from traditional supply chain contracting literature in three aspects. First, we consider a SC with two competing retailers facing stochastic demand that is sensitive to both sales effort and retail price. Second, we develop a new linear demand model that could better represent the sensitivity of each retailer demands to the prices and sales efforts mutually. Third, our simulation optimization decision support tool could make it possible for us to analyze contracts' effects and investigate exerting different contracts.

\section{PROBLEM FORMULATION}

\subsection{Model Assumptions}

The trading process is defined as follows. The supplier sets the identical wholesale price $W$ for two competing retailers. According to the retail price, their marginal costs and common market demand, the retailers determine their orders quantity. We suppose that the retailers could sell their unsold goods at the end of the selling season at the price of the salvage value. The model is based on some principle assumptions as follows:

- The model is based on price and effort dependent stochastic demand.

- The retailers competing factors affect the demand.

- The two retailers are equally powerful to compete in one common market.

- The price and sales effort are retailer tools to enhance their market shares.

- The supplier has infinite production capacity and the production is adjusted according to the market demand.

- Salvage value, goodwill value and marginal costs are equal at both retailers.

- Contract parameters are equal for both retailers.

\subsection{Notations and Mathematical Formulation}

We follow mathematical formulation from the centralized supply chain to the coordinated decentralized supply chain with contracts. Preceding model development, the notations are described as follows:

\section{Model parameters}

$S_{s} \quad$ salvage value per unit at the end of period at the supplier

$G_{s} \quad$ goodwill cost at supplier per shortage unit

$C_{s} \quad$ production cost per unit at the supplier

$S_{r} \quad$ salvage value per unit at the end of period at the retailers

$G_{r} \quad$ goodwill cost at retailers per shortage unit 
$C_{r} \quad$ marginal cost at the retailers per unit

$W \quad$ wholesale price

Decision variables in the cases of Decentralized SC and Centralized SC

$S Q \quad$ supplier production quantity

$Q_{s c}$ order quantities of supply chain

$P_{r 1}$ the retail price at the retailer number one

$P_{r 2}$ the retail price at the retailer number two

$e_{r 1}$ the effort level at the retailer number one to promote sales

$e_{r 2}$ the effort level at retailer number two to promote sales

$Q_{r 1}$ order quantity of the retailer number one

$Q_{r 2}$ order quantity of the retailer number two

\section{Decision variables for contracts (buyback and revenue sharing)}

$\beta \quad$ the return credit (buyback rate)

$\varphi \quad$ the fraction of retailers' revenue shared with supplier

$W^{R S}$ wholesale price in the Revenue Sharing contract

\section{Performance measures}

$\Pi_{j}^{i}$ denotes expected profits of supply chain member $j$ in the case of contract/noncontract $i$, where $j=\{r l$ : retailer one, $r 2$ : retailer two, $s$ : supplier, $s c$ : supply chain $\}$ and $i=\{R S$ : Revenue Sharing, $B B$ : Buyback, $S C$ : integrated or centralized supply chain, $N C$ : No coordination $\}$

\subsubsection{Price and Effort Dependent Demand}

The price and effort dependent stochastic demand regarding competition factors between retailers awfully affect our mathematical and simulation model. The price dependent demand for two competing retailers in a common market is defined as Eq. (1) in the marketing literature (Yao et al. 2008, 2009; Padmanabhan and Png 1997; Jeuland and Shugan 1998).

$$
D_{r i}\left(P_{r i}, P_{r j}\right)=\alpha-\lambda P_{r i}+\gamma P_{r j} \quad i=1,2 \text { and } j=3-i
$$

Where $P_{r i}$ denotes the price at the retailer i, $\alpha$ represents the original demand of the common market for retailer $i, \lambda$ represents retailer i store-level factor that affect consumers' sensitivity to retail price and $\gamma$ denotes the competitive factor. To make price and effort dependent demand stochastic, a random variable $\mu$, with density function $f$ and cumulative distribution function $F$ is added to the $D_{r i}\left(P_{r i}, P_{r j}\right)$, as shown in Eq.(2).

$$
X_{i}=D_{r i}\left(P_{r i}, P_{r j}\right)+\mu \quad i=1,2 \text { and } j=3-i
$$

Although Eq. (2) does not satisfy all the competitive market conditions but it is worth using it as an acceptable price dependent demand function (Yao et al. 2009). It is important to recognize that in real markets, different price intervals affect the store-level factor and competitive factor. It means that in the case of higher prices, a rise in selling prices of 1 dollar decreases the primary demand more than the case of rise of 1 dollar in lower selling prices. Also, when the selling prices at the retailers pass the market thresholds, it is realistic that they will lose more loyal customers than before. In brief, Eq. (2) does not consider the price dependent nature of competing factor and store-level factor.

In this paper we try to improve the price dependent stochastic demand function such that competitive factors and store-level factors updating through different prices thresholds $\left(\eta_{1}, \eta_{2}, \eta_{3}\right)$ are considered. We 


\section{Eskandari, Darayi and Geiger}

suppose that store-level factor $\lambda_{i k}$ and competitive factor $\gamma_{i l}$ changes through three different price intervals. We develop a new competitive price and effort dependant stochastic demand function as follows in Eq.(3).

$$
\begin{aligned}
& D_{r i}\left(P_{r i}, P_{r j}, e_{r i}, e_{r j}\right)=\alpha-\lambda_{i k} *\left(P_{r i}-\eta_{k}-1\right)+\gamma_{i l} *\left(P_{r j}-P_{r i}\right)+¥ * e_{r i}-\psi * e_{r j} \\
& i=1,2 \text { and } j=3-i \text { and } k=1,2,3 \\
& \text { IF } P_{r i} \geq \eta_{3} \text { Then } k=3 \\
& \text { IF } \eta_{b_{2}} \leq P_{r i}<\eta_{3} \text { Then } k=2 \\
& \text { IF } P_{r i}<\eta_{2} \quad \text { Then } k=1 \\
& \lambda_{i 1}<\lambda_{i 2}<\lambda_{i 3} \\
& n_{1}<n_{2}<n_{3} \\
& X_{i}\left(P_{r i}, P_{r j}, e_{r i}, e_{r j}, \varepsilon\right)=D_{r i}\left(P_{r i}, P_{r j}, e_{r i}, e_{r j}\right)+\mu
\end{aligned}
$$

Where common notations have the same meanings as the traditional price dependent stochastic demand function in marketing literature. We define $\eta_{k}$ as a market selling price threshold. Considering market sensitivity to the rise of price at retailers in different intervals, we could appraise $\eta_{k}\left(\eta_{1}, \eta_{2}, \eta_{3}\right)$. Let $\lambda_{i k}$ be the store-level factor at retailer $i$ which is influenced by selling price at this retailer. We use $\gamma_{i l}$ as a competitive factor which is affected by selling price at the rival retailer. Let $e_{r i}$ represents a single effort level at the retailer $i$ to show the retailer activities to promote the sales, $¥$ and $\psi$ represent effort level effect and rival effort level impact on the market primary demand sequentially. We use $X_{i}$ as a function to consider the randomness in market demand. Here $\mu$ denotes the random variable that realizes the stochastic feature of the market demand. Considering market demand variability, we could fit the best distribution function to the $\mu$. Here, we suppose that $\mathrm{f}$ and $\mathrm{F}$ represent probability density function and cumulative distribution function of $\mu$ consecutively.

\subsubsection{Cases of No Coordination}

To realize the usefulness of contracts in supply chain coordination, four cases have been developed. The first one is of 'Decentralized SC' in which SC members act independently. The retailers decide their selling prices, effort levels and order quantities considering their own profit. The second one is of 'Centralized SC' in which decision variables are defined considering sum of supply chain members' profit as an objective function. It has been shown that in the case of 'Centralized SC' retailers profits diminishes in comparison with the case of 'Decentralized SC' (He et al. 2009). In the third and fourth cases we explore a decision variable set in which coordination is realized through RS or buyback contract.

\section{Case 1: Decentralized SC}

In the case of 'Decentralized SC' supply chain members act independently. Considering their own profit function, each retailer determines selling prices, effort levels and order quantities. Let $S_{r i}\left(Q_{r i}, P_{r i}, P_{r j}, e_{r i}, e_{r j}\right)$ represent retailer $i$ expected sales, $I_{r i}\left(Q_{r i}, P_{r i}, P_{r j}, e_{r i}, e_{r j}\right)$ represent retailer $i$ expected left over inventory and $G W_{r i}$ denote retailer $i$ goodwill value that is lost because of the inventory shortage. These are shown as follows in Eq. (4), Eq. (5) and Eq. (6).

$$
\begin{aligned}
& S_{r i}\left(Q_{r i}, P_{r i}, P_{r j}, e_{r i}, e_{r j}\right)= \begin{cases}Q_{r i} & I F \quad Q_{r i} \leq X_{i}\left(P_{r i}, P_{r j}, e_{r i}, e_{r j}, \mu\right) \\
X_{i}\left(P_{r i}, P_{r j}, e_{r i}, e_{r j}, \mu\right) & \text { IF } Q_{r i}>X_{i}\left(P_{r i}, P_{r j}, e_{r i}, e_{r j}, \mu\right)\end{cases} \\
& L_{r i}\left(Q_{r i}, P_{r i}, P_{r j}, e_{r i}, e_{r j}\right)=\left\{\begin{array}{c}
Q_{r i}-S_{r i}\left(Q_{r i}, P_{r i}, P_{r j}, e_{r i}, e_{r j}\right) \text { IF } Q_{r i}>X_{i}\left(P_{r i}, P_{r j}, e_{r i}, e_{r j}, \mu\right) \\
0
\end{array}\right.
\end{aligned}
$$




$$
G W_{r i}\left(Q_{r i}, P_{r i}, P_{r j}, e_{r i}, e_{r j}\right)=\left\{\begin{array}{c}
X_{i}\left(P_{r i}, P_{r j}, e_{r i}, e_{r j}, \mu\right)-Q_{r i} I F Q_{r i}<X_{i}\left(P_{r i}, P_{r j}, e_{r i}, e_{r j}, \mu\right) \\
0 \quad \text { Otherwise }
\end{array}\right.
$$

The retailers' profit function is given in Eq. (7). Here $g\left(e_{r i}\right)$ represents the retailer's cost of making an effort level $e_{r i}$. Retailers' profit function consists of revenues from selling product and salvages minus cost of lost goodwill value, selling effort and ordering costs.

$$
\begin{aligned}
\Pi_{r i}^{N C}= & P_{r i}\left(S_{r i}\left(Q_{r i}, P_{r i}, P_{r j}, e_{r i}, e_{r j}\right)\right)-C_{r}\left(Q_{r i}\right)-G_{r}\left(G W_{r i}\right)-W\left(Q_{r i}\right)-g\left(e_{r i}\right) \\
& +S_{r}\left(L_{r i}\left(Q_{r i}, P_{r i}, P_{r j}, e_{r i}, e_{r j}\right)\right) \quad i=1,2
\end{aligned}
$$

Thus, the optimal policy for each retailer is obtained by maximizing expected profit function Eq. (8).

$$
\begin{aligned}
& \text { Maximize } E\left[\Pi_{r i}^{N C}\left(P_{r i}, e_{r i}, Q_{r i}\right)\right] \\
& P_{r i}, P_{r j}, e_{r i}, e_{r j}, Q_{r i}, Q_{r j} \\
& \text { s.t.: } \\
& \quad P_{r i}, P_{r i}, e_{r i}, e_{r i}, Q_{r i}, Q_{r i} \geq 0
\end{aligned}
$$

Here, it is realistic for each retailer to consider her/his rival's expected profit function, because as shown in Eq. (3) selling prices and effort levels of the retailers affect their market demand mutually. Thus, in this paper we consider Eq. (9) as an objective function to set the decision variables in the case of 'No coordination'.

$$
\begin{aligned}
& \text { Maximize }\left\{\operatorname{Min}\left\{E\left[\Pi_{r i}^{N C}\right], E\left[\Pi_{r j}^{N C}\right]\right\}\right\} \quad i=1,2 \text { and } j=3-i \\
& \quad P_{r i}, P_{r j}, e_{r i}, e_{r j}, Q_{r i}, Q_{r j} \\
& \quad \text { s.t: } \\
& \quad P_{r i}, P_{r j}, e_{r i}, e_{r j}, Q_{r i}, Q_{r j} \geq 0
\end{aligned}
$$

\section{Case 2: Centralized SC}

In the case of 'Centralized SC; the whole SC system is considered as a single entity whose expected profit needs to be optimized. Hence, the decision variables are set such that they satisfy Eq. (10).

$$
\begin{gathered}
\Pi_{s c}^{S C}=P_{r i} S_{r i}\left(Q_{r i}, P_{r i}, P_{r j}, e_{r i}, e_{r j}\right)+S_{r} L_{r i}\left(Q_{r i}, P_{r i}, P_{r j}, e_{r i}, e_{r j}\right)-G_{r} G W_{r i}-C_{r} Q_{r i}-g\left(e_{r i}\right) \\
+P_{r j} S_{r j}\left(Q_{r j}, P_{r i}, P_{r j}, e_{r i}, e_{r j}\right)+S_{r} L_{r j}\left(Q_{r j}, P_{r i}, P_{r j}, e_{r i}, e_{r j}\right)-G_{r} G W_{r j} \\
-g\left(e_{r j}\right)-C_{s} S Q+S_{r}\left(S Q-Q_{r i}-Q_{r j}\right)-G_{s} G W_{s} \quad i=1,2 \text { and } j=3-i \\
\text { Maximize } E\left[\Pi_{s c}^{S C}\right] \\
P_{r i}, P_{r j}, e_{r i}, e_{r j}, Q_{r i}, Q_{r j} \\
\text { s.t.: } \\
P_{r i}, P_{r j}, e_{r i}, e_{r j}, Q_{r i}, Q_{r j} \geq 0
\end{gathered}
$$

It has been shown that in the case of 'Centralized SC' retailers' profits diminished in comparison with the case of 'no coordination' (Arshinder et al. 2009). Although, some researchers such as He et al. (2009) show that RS and buyback contracts couldn't coordinate a SC with price and effort dependent stochastic 


\section{Eskandari, Darayi and Geiger}

demand, our new demand function as shown in Eq. (3) makes it possible for us to coordinate the SC by tuning the contract parameters. The complexity of the model and its random characteristics make it difficult for us to solve the problem analytically. As it will be discussed later, numerical experiment in Section 4 and the significant half-widths for each performance measure show that uncertainty is a big issue in this problem. Thus, in this paper we use simulation optimization approach as a decision support tool to pursue a set of decision variables that coordinate the SC using RS or buyback contracts.

\subsubsection{Coordination with Contract}

The retailers may not be interested to be the part of a Centralized SC due to the reduction in their profits. The supply chain contracts are used to mutually share risks and rewards. We say that a contract coordinates a SC if exerting the contract let the SC keep its Centralized case's decision variables set and each SC member's profit is at least as much as the case of No coordination.

\section{Case 3: Coordination with buyback contract}

With a buyback contract the supplier pays the retailers $\beta$ per unit remaining at the end of the period. A retailer should not profit from leftover inventory, so assume $\beta \leq \mathrm{W}$ (Cachon, 2003). Fixing the decision variables are found in the Centralized case, we try to find $\beta$ value through the Eq. (11)

$$
\begin{array}{cl}
\operatorname{Maximize} & \left\{\operatorname{Min}\left[\Pi_{r i}^{B B} / \Pi_{r i}^{D C}, \Pi_{r j}^{B B} / \Pi_{r j}^{D C}, \Pi_{s}^{B B} / \Pi_{s}^{S C}\right]\right\} \\
\text { s.t.: } & i=1,2 \text { and } j=3-i \\
& \Pi_{r i}^{B B} \geq \Pi_{r i}^{N C} \\
& \Pi_{r j}^{B B} \geq \Pi_{r i}^{N C} \\
& \Pi_{s}^{B B} \geq \Pi_{s}^{N C} \\
& \beta \leq W
\end{array}
$$

\section{Case 4: Coordination with revenue sharing contract}

With a RS contract the supplier decreases the wholesale price to $W^{R S}$, in return retailers share revenue of selling products and salvages with the supplier. Let $1-\varphi$ be the fraction of supply chain revenue the retailers keep, so $\varphi$ is the fraction supplier earns (Cachon, 2003; Arshinder et al. 2009). Fixing the decision variables are found in the Centralized case, we try to find $\varphi$ and $W^{R S}$ value through Eq. (12).

$$
\begin{gathered}
\underset{\varphi, W^{R S}}{\operatorname{Maximize}}\left\{\operatorname{Min}\left[\Pi_{r i}^{R S} / \Pi_{r i}^{D C}, \Pi_{r j}^{R S} / \Pi_{r j}^{D C}, \Pi_{s c}^{R S} / \Pi_{s}^{S C}\right]\right\} \\
\text { s.t.: } \quad i=1,2 \text { and } j=3-i \\
\Pi_{r i}^{R S} \geq \Pi_{r i}^{D C} \quad \Pi_{r j}^{R S} \geq \Pi_{r i}^{D C} \\
\Pi_{s}^{R S} \geq \Pi_{s}^{N C} \\
0 \leq \varphi \leq 1
\end{gathered}
$$




\section{DECISION SUPPORT TOOL}

In this paper we use simulation optimization approach as a decision support tool to pursue a set of decision variables that coordinate the SC using revenue sharing or buyback contract. Simulation can be used to study processes that are too complex to permit analytical model formulation and/or evaluation (Sarhangian et al. 2008). The mathematical model illustrated in Section 2 is too complex to analytically evaluate and find optimum or close to optimum set of contract parameters to coordinate the SC. Above all, the uncertain nature of demand and its effect on the performance measures could satisfy our use of simulation optimization as a decision support tool. Significant half-widths resulted in the numerical example just for a normal demand with zero mean and moderate standard deviation confirm that uncertainty is a big issue here in this problem. We develop a simulation model using popular Arena software (Kelton et al. 2007). OptQuest optimization software which is provided with Arena helps us finding optimum or close to optimum set of contract parameters.

\subsection{Simulation Model}

Simulation can be used to study processes that are too complex to permit analytical model formulation and/or evaluation. The mathematical model illustrated in Section 2 is too complex to analytically evaluate and find optimum or close to optimum set of contract parameters to coordinate the SC. The complexity can be due to the stochastic nature of the market demand $(\mu)$ and the interaction between decision variables $\left(P_{r i}, P_{r j}, e_{r i}, e_{r j}, Q_{r i}, Q_{r j}\right)$. Simulation model can adequately map the real world systems, as they actually exist. In this case, a simulation model is used to estimate the output performance measure, here called as objective function, of the complex system.

In this study, the popular Arena software is used to build a simulation model for the described SC with stochastic price and effort dependent competitive market demand (Figure 1). The model is verified by developing the model in a modular manner, substituting constants for random variables and manually checking the results.

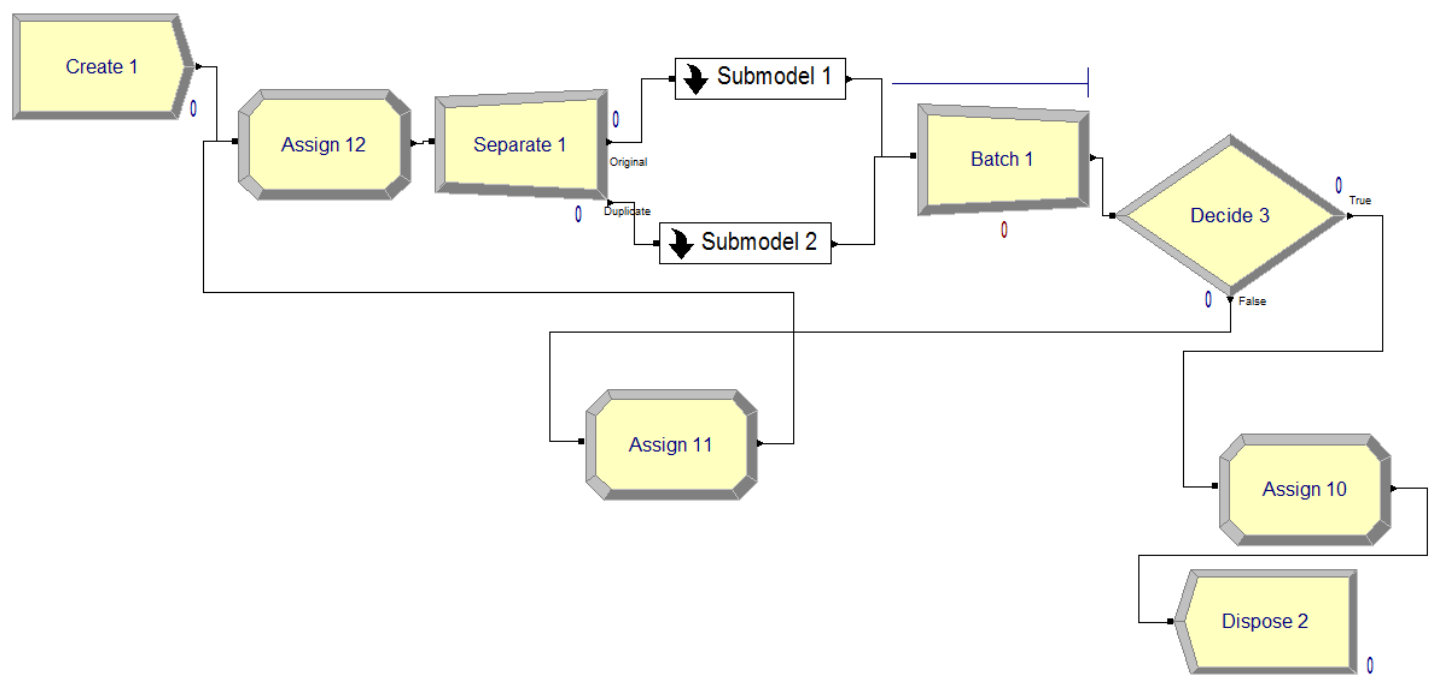

Figure 1: General simulation model with Arena

Figure 2 presents a conceptual illustration of the proposed simulation model. This is a general framework of what exactly occurs in simulation runs for each entity, which is a market demand. 


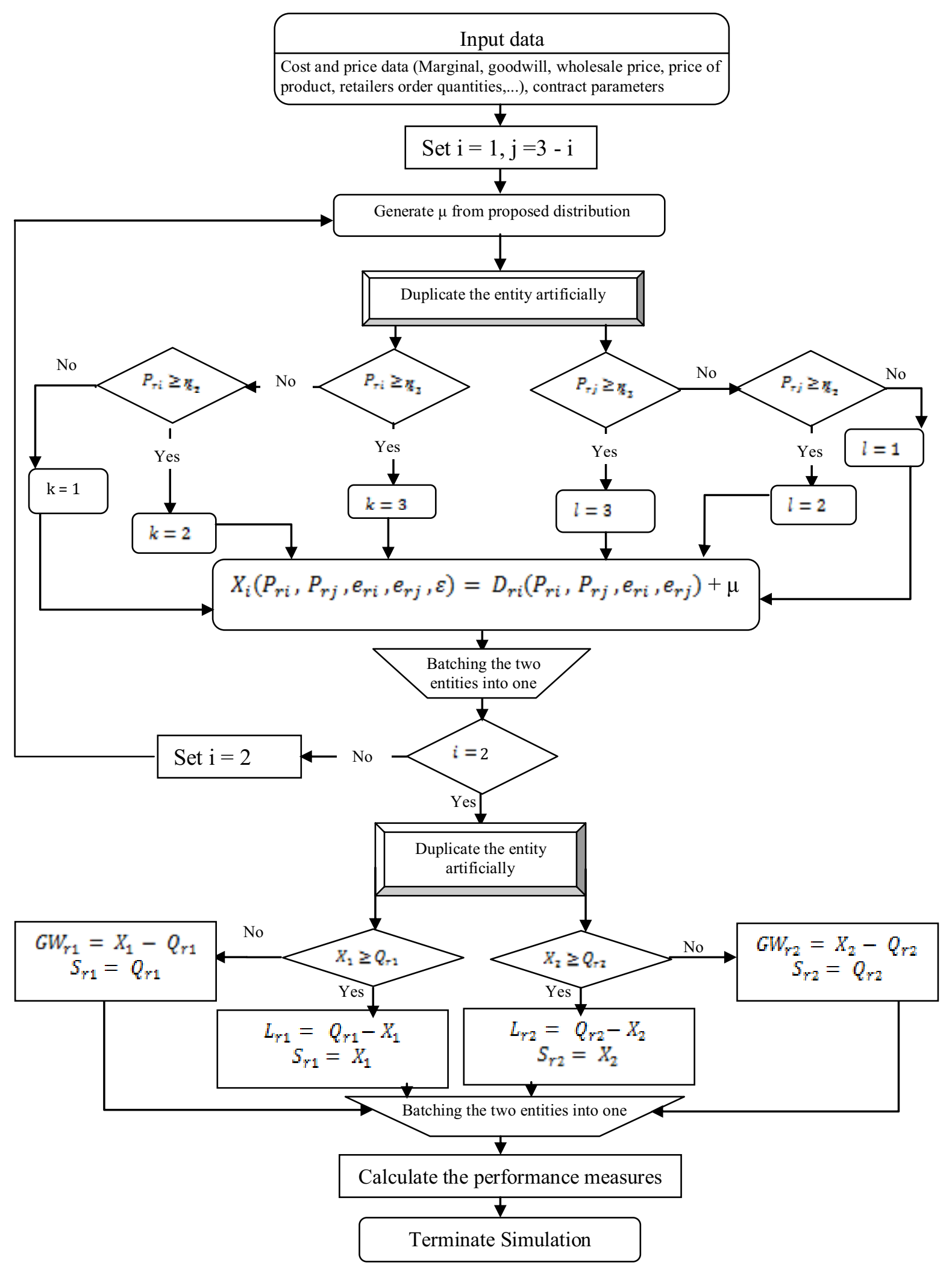

Figure 2: A conceptual illustration of the proposed simulation model 


\subsection{Simulation Optimization}

The complexities and uncertainties in real world systems are the main reason that simulation is often chosen as a basis for handling the decision problems associated with those systems. The optimization of simulation models often deals with the situation in which the interest is to find which of a large number of sets of model specifications lead to optimal output performance (April et al. 2003). One of the popular methods to optimize simulated systems is using metaheuristics. In this mechanism, simulation model is treated as a black-box, i.e. only the inputs and outputs of the simulation model are observed. At each iteration, the metaheuristic optimizer chooses a set of values for input variables and uses the output value generated by the simulation model to make decision regarding the selection of the next trial solution with the goal of finding optimal values for decision variables.

In this study, we use OptQuest optimization software, which is provided with Arena, to find the optimum or close to optimum set of contract parameters. OptQuest, combines the metaheuristics of Tabu search, Scatter search and Neural Networks into a single, composite search algorithm to provide maximum efficiency in identifying new scenarios (April et al. 2003; Glover et al. 2000). In this problem, OptQuest searches for the best set of decision variables $\left(P_{r i}, P_{r j}, e_{r i}, e_{r j}, Q_{r i}, Q_{r j}\right)$ in the cases of Centralized SC and Decentralized SC to maximize SC profit function (11) and retailers profits function (9) subsequently. Then, we run the simulation model using these sets of decision variables, and save the outputs in each cases. Fixing the decision variables as their values in the case of Centralized SC and using outputs of the case of Decentralized supply chain as constraints for the optimization model $(11,12)$, we use OptQuest to search the best set of contract parameters $\left(W^{R S}, \varphi, \beta\right)$ that coordinate the SC in the case of exerting each contract (Figure 3).

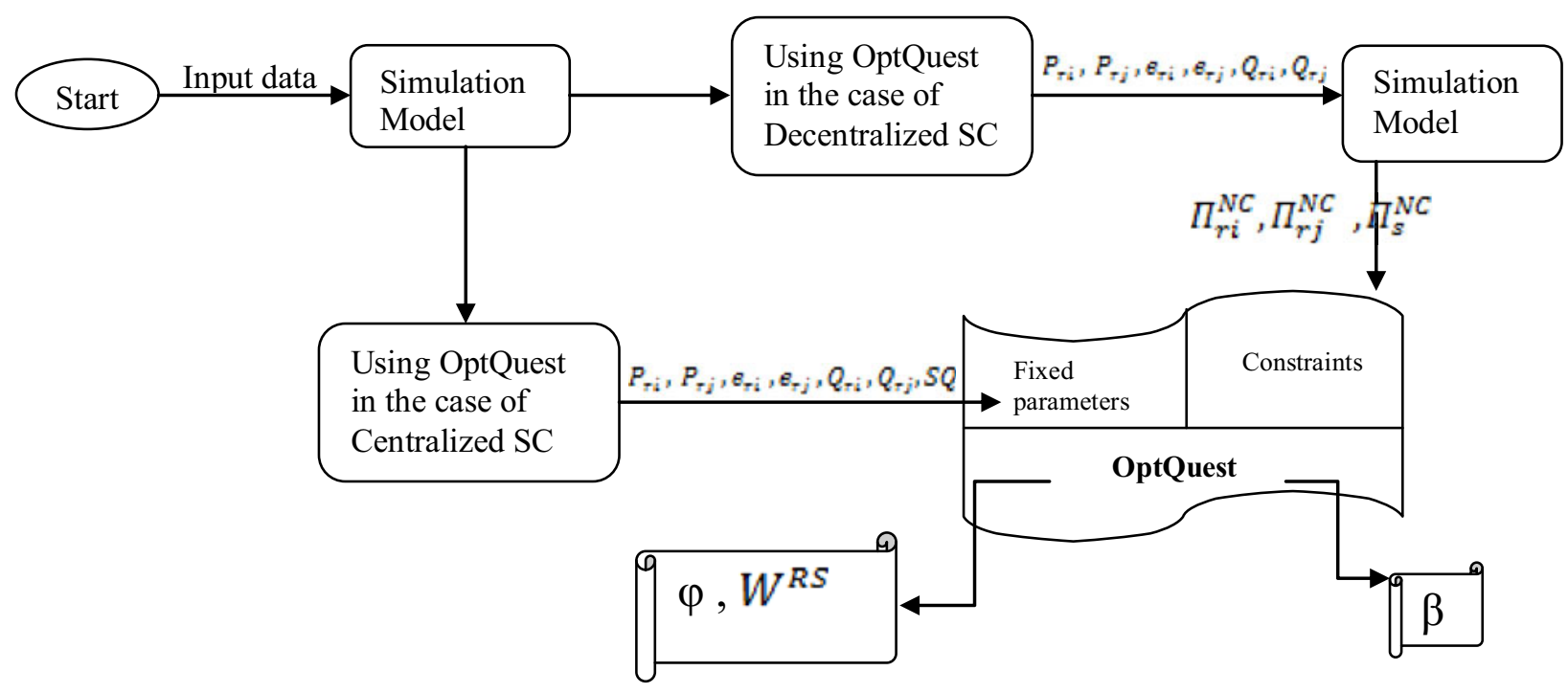

Figure 3: Simulation Optimization Based Decision Support Tool

\section{NUMERICAL EXAMPLE}

In this section, we will use a numerical example to illustrate how our simulation optimization decision support tool can help us exert revenue sharing or buyback to coordinate a SC. Experimental parameters are listed in Table 1. Adjusting simulation model parameters through Table 1, we use OptQuest tool to find the decision variable set $\left(P_{r i}, P_{r j}, e_{r i}, e_{r j}, Q_{r i}, Q_{r j}, S Q\right)$ in the case of Decentralized supply chain and Centralized SC through Eq. (9) and Eq. (10). Number of replications is 


\section{Eskandari, Darayi and Geiger}

set to 35. Some of the control variables such as $Q_{r i}, Q_{r j}, S Q$ are set as a discrete variable to represent the real market condition. The optimum or near optimum set of decision variables is shown in Table 2 .

Table 1: Parameters set used in the Numerical Example

\begin{tabular}{|lllll|}
\hline$S_{s}: 6$ & $\alpha: 200$ & $\eta_{2}: 26$ & $\mu: \operatorname{NORM}(0,30)$ & $\gamma_{i 3}: 15$ \\
$G_{s}: 10$ & $\lambda_{i 1}: 10$ & $\eta_{3}: 30$ & $\gamma_{i 2}: 10$ & $\gamma_{i 1}: 5$ \\
$C_{s}: 12$ & $\lambda_{i 2}: 15$ & $¥: 20$ & $C_{r}: 2$ & \\
$W: 20$ & $\lambda_{i 3}: 30$ & $\psi: 5$ & $G_{r}: 14$ & \\
$S_{r}: 4$ & $\eta_{1}: 23$ & $g\left(e_{r i}\right)=\delta e_{r i}^{2} / 2$ & $\mho: 100$ & \\
\hline
\end{tabular}

Table 2: Optimum solutions obtained from the OptQuest

\begin{tabular}{|c|c|c|c|c|c|c|c|c|c|c|c|}
\hline \multirow{3}{*}{ Case } & \multicolumn{7}{|c|}{ Outputs of the OptQuest } & \multicolumn{4}{|c|}{$\begin{array}{l}\text { Performance measures for the optimum solutions } \\
\text { with } 95 \% \text { confidence interval }(\alpha=.05)\end{array}$} \\
\hline & \multirow[b]{2}{*}{$P_{r 1}$} & \multirow[b]{2}{*}{$P_{r 2}$} & \multirow[b]{2}{*}{$e_{r 1}$} & \multirow[b]{2}{*}{$e_{r 2}$} & \multirow[b]{2}{*}{$Q_{r 1}$} & \multirow[b]{2}{*}{$Q_{r 2}$} & \multirow[b]{2}{*}{$S Q$} & $\Pi_{r 1}^{i}$ & $\Pi_{r 2}^{i}$ & $\Pi_{s}^{i}$ & $\Pi_{s c}^{i}$ \\
\hline & & & & & & & & $\begin{array}{cl}\text { Mean } & \\
\pm & \text { Half- } \\
& \text { Width }\end{array}$ & $\begin{array}{c}\text { Mean } \\
\pm \quad \text { Half- } \\
\\
\quad \text { Width }\end{array}$ & $\begin{array}{cl}\text { Mean } & \\
\pm & \text { Half- } \\
& \text { Width }\end{array}$ & $\begin{array}{c}\text { Mean } \\
\pm \quad \text { Half- } \\
\quad \text { Width }\end{array}$ \\
\hline $\begin{array}{c}\text { No } \\
\text { Coordination } \\
\text { (i: NC) }\end{array}$ & 30.97 & 29.19 & 1.00 & 1.00 & 139 & 172 & 342 & \begin{tabular}{|cc}
$\begin{array}{c}742.88 \\
\pm\end{array}$ & \\
& 94.42 \\
\end{tabular} & $\begin{array}{r}745.44 \\
\pm \\
\quad 89.71 \\
\end{array}$ & \begin{tabular}{|l}
$\begin{array}{c}2302.36 \\
\pm\end{array}$ \\
\end{tabular} & \begin{tabular}{|l}
$\begin{array}{l}3790.31 \\
\quad \pm\end{array}$ \\
\end{tabular} \\
\hline $\begin{array}{c}\text { Centralized } \\
\text { SC } \\
\text { (i: SC) }\end{array}$ & 30.04 & 26.00 & 2.03 & 1.92 & 202 & 294 & 516 & $\stackrel{622.20}{ \pm} 235.74$ & $\stackrel{344.35}{ \pm}$ & $\stackrel{3848.84}{ \pm} \quad 89.02$ & $\stackrel{4}{4814.55}^{ \pm}$ \\
\hline
\end{tabular}

Figure 4 presents the coverage of the OptQuest's algorithm in the case of Centralized SC. Running the simulation model with the results of the OptQuest helps us to identify constraints of the cases of coordination with contracts through Eq. (11) and Eq. (12).

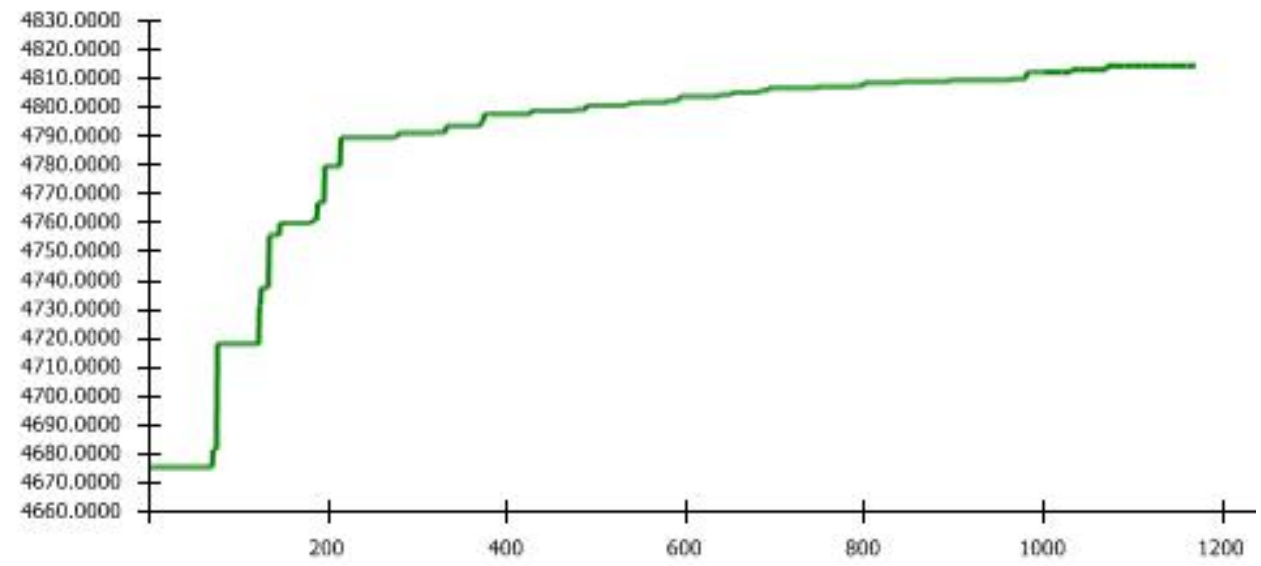

Figure 4: OptQuest optimum window for the Integrated Supply Chain

Fixing the decision variables as their values in the case of Centralized SC and using simulation results of the case of Decentralized supply chain as constraints for the optimization model $(11,12)$, we use OptQuest to search the best set of contract parameters $\left(W^{R S}, \varphi, \beta\right)$ that coordinate the SC in the case of exerting each contract. Table 3 presents the optimal set of contract parameters that coordinate the SC. 
Figure 5 and 6 present the coverage of the OptQuest's algorithm in the case of Coordination with contracts. The red line represents infeasible solutions and green line depicts feasible solutions.

Table 3: Outputs of the OptQuest for the case of Coordination with contracts

\begin{tabular}{|c|c|c|c|c|c|c|c|c|}
\hline \multirow{4}{*}{$\begin{array}{l}\text { Coordination } \\
\text { with Contract }\end{array}$} & \multicolumn{3}{|c|}{ Contract parameters } & \multirow{2}{*}{\multicolumn{4}{|c|}{ Simulation results using OptQuest outputs }} & \multirow{4}{*}{$\begin{array}{l}\text { Contract } \\
\text { Efficiency }\end{array}$} \\
\hline & \multicolumn{2}{|c|}{$\begin{array}{l}\text { Revenue } \\
\text { Sharing }\end{array}$} & \multirow{3}{*}{$\begin{array}{c}\text { Buyback } \\
\beta\end{array}$} & & & & & \\
\hline & \multirow{2}{*}{$\varphi$} & \multirow{2}{*}{$W^{R S}$} & & $\Pi_{r 1}^{i}$ & $\Pi_{r 2}^{i}$ & $\Pi_{s}^{i}$ & $\Pi_{s c}^{i}$ & \\
\hline & & & & Mean $\pm \begin{array}{c}\text { Half- } \\
\text { Width }\end{array}$ & $\begin{array}{cc}\text { Mean } & \text { Half- } \\
\pm & \text { Width }\end{array}$ & Mean $\pm \quad \begin{array}{l}\text { Half- } \\
\text { Width }\end{array}$ & $\begin{array}{ll}\text { Mean } \pm & \text { Half- } \\
& \text { Width }\end{array}$ & \\
\hline $\begin{array}{c}\text { Revenue Sharing } \\
\text { i: RS }\end{array}$ & 0.487 & 6.882 & & $\begin{array}{cc}\begin{array}{l}751.99 \\
\pm\end{array} \\
\end{array}$ & $\begin{array}{c}835.62 \\
\pm\end{array}$ & $\begin{array}{c}3227.57 \\
\pm \quad 200.72 \\
\end{array}$ & $\begin{array}{c}4814.55 \\
\pm\end{array}$ & 0.833 \\
\hline $\begin{array}{l}\text { Buyback } \\
\text { i: } \beta\end{array}$ & & & 18.523 & \begin{tabular}{|ll}
1055.63 & \\
\pm & 86.15
\end{tabular} & $\begin{array}{ll}755.83 & \\
\pm & 49.73\end{array}$ & $\begin{array}{cc}3119.45 & \\
\pm & 200.72\end{array}$ & $\begin{array}{cc}814.55 & \\
\pm & 366.92\end{array}$ & 0.796 \\
\hline
\end{tabular}

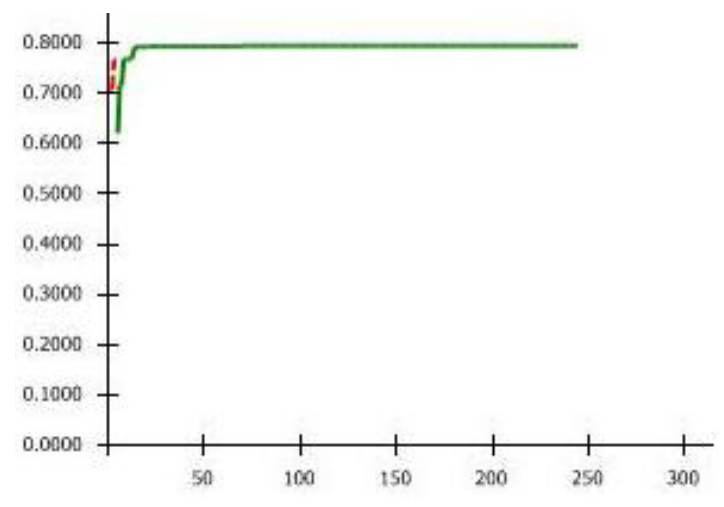

Figure 5: OptQuest optimum window for the coordinated supply chain using Buyback contract case

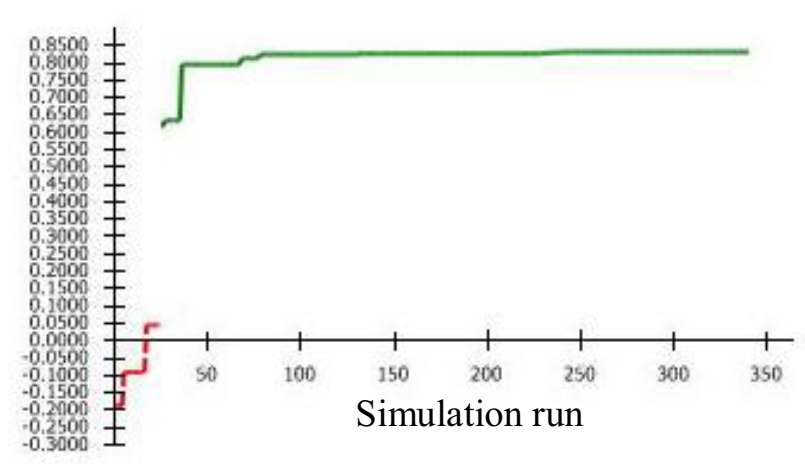

Figure 6: OptQuest optimum window for the coordinated supply chain using Revenue Sharing contract case

\section{CONCLUSIONS}

In this paper, using simulation optimization we develop a decision support tool for SCC with contracts. Channel coordination for a SC consisting one supplier and two retailers, facing stochastic demand that is sensitive to both sales effort and retail price is studied. We propose a new linear demand model in order to represent a real competitive price and effort dependent sensitivity. Due to the stochastic nature of the market demand and the interaction between decision variables, simulation is the most appropriate tool employed to model/analyze the SCC with contracts problem. Our simulation optimization decision support tool is then used to find the optimum or near optimum set of decision variables in the cases of Centralized SC or coordinated supply chain using contracts. Solving such problems with traditional mathematical techniques are usually time consuming and subject to rather restricting assumptions. The use of simulation modeling and optimization in the supply chain contracts problem has allowed us to effectively analyze and solve the problem in order to realize the channel coordination.

There are many interesting avenues for future research. In this paper we assume a two-stage supply chain. The model can be extended to consider a three-stage supply chain consisting a manufacturer, distributer and retailer facing such a price and effort dependent stochastic demand. 


\section{Eskandari, Darayi and Geiger}

\section{REFERENCES}

April, J., F. Glover, J. P. Kelly, and M. Laguna. 2003. Practical Introduction to simulation optimization. In Proceedings of the 2003 Winter Simulation Conference, ed. S. Chick, P. J. Sanchez, D. Ferrin, and D. J. Morrice, 71-78. Piscataway, New Jersey: Institute of Electrical and Electronics Engineers, Inc.

Arshinder, A. Kanda, and S. G. Deshmukh. 2008. SC coordination: Perspectives, empirical studies and research directions. Int. j. Production Economics 115:316-335.

Arshinder, A. Kanda, and S. G. Deshmukh. 2009. A framework for evaluation of coordination by contracts: A case of two-level SCs. Computer \& Industrial Engineering 56:1177-1191.

Cachon, G. P. 2003. SC coordination with contracts. In Handbooks in Operation Research and Management Science, ed. A. G. Kok and S. C. Graves, vol. 11.229-340. Boston: Elsevier.

Giannoccaro, I., and P. Pontrandolfo. 2004. SC coordination by revenue sharing contracts. Int. $j$. Production Economics 89:131-139.

Glover, F., M. Laguna, and R. Matri. 2000. Fundamentals of Scatter search and path relinking. Control and cybernetics 29(3):653-684.

He, Y., X. Zhao, L. Zhao, and J. He. 2009. Coordination a SC with effort and price dependent stochastic demand. Applied Mathematical Modeling 33:2777-2790.

Kelton, W. D., R. P. Sadowski, and D. T. Sturrock. 2007. Simulation with Arena . 4rd ed. New York: McGrawHill, Inc.

Li, X., and Q. Wang. 2007. Coordination mechanisms of SC systems. European Journal of Operational Research 179:1-16.

Padmanabhan, V., and I. P. L. Png. 1997. Manufacturer's returns policies and retail competition. Marketing Science 16:81-94.

Sarhangian, V., A. Vaghefi, H. Eskandari, and M. K. Ardakani. 2008. Optimizing inspection strategies for multi-stage manufacturing processes using simulation optimization. In Proceeding of the 2008 Winter Simulation Conference, ed. S. J. Mason, R. R. Hill, L. Monch, O. Rose, T. Jefferson, and J. W. Fowler, 1974-1980. Piscataway, New Jersey: Institute of Electrical and Electronics Engineers, Inc.

Yao, Z., S. C. H. Leung, K. K. Lai. 2008. Manufacturer's revenue-sharing contracts and retail competition. European Journal of Operational Research 186:637-651.

\section{AUTHOR BIOGRAPHIES}

HAMIDREZA ESKANDARI is an Assistant Professor of Industrial Engineering and director of advanced simulation lab at the Tarbiat Modares University, Tehran, Iran. He received his Bachelor's degree in Electrical Engineering from the University of Tehran (1998), his Master's degree in SocioEconomic Systems Engineering from the Iran University of Science and Technology (2001) and his Ph.D. in Industrial Engineering from the University of Central Florida (2006). His research interests include Simulation Modeling and Analysis, Simulation Optimization, and Evolutionary Multi objective Optimization. His email address is <eskandari@modares.ac.ir>.

MOHAMAD DARAYI is a Master's student in the Department of Industrial Engineering at Tarbiat Modares University. His research interests include Simulation Modeling and Analysis, Simulation Optimization, and Supply Chain Coordination with Contracts. His email address is $<$ m.darayi@modares.ac.ir>.

CHRISTOPHER D. GEIGER is an Associate Professor in the Department of Industrial Engineering and Management Systems at the University of Central Florida in Orlando, FL. His research and teaching interests include simulation modeling and analysis, machine learning in production planning and scheduling and heuristic optimization. He is a member of IIE, INFORMS and SME. His e-mail address is <cdgeigeremail.ucf.edu>. 